\title{
Comparative Assessment of Different PCR-Based Typing Methods of Pseudomonas aeruginosa Isolates
}

\author{
Shaymaa H Abdel- \\ Rhman (iD) ${ }^{1,2}$ \\ Dina E Rizk (iD) \\ 'Department of Microbiology and \\ Immunology, Faculty of Pharmacy, \\ Mansoura University, Mansoura, Egypt; \\ ${ }^{2}$ Department of Pharmaceutics and \\ Pharmaceutical Biotechnology, Faculty of \\ Pharmacy, Taibah University, AlMadinah \\ Al Munawwarah, Saudi Arabia
}

This article was published in the following Dove Press journal: Infection and Drug Resistance

Introduction: Pseudomonas aeruginosa is one of the important causes of nosocomial infections. Analyzing the diversity of these isolates is important to control the diseases caused by them. Studies of molecular epidemiology depend on the application of typing methods.

Purpose: This study aims to assess the performance of PCR- based typing techniques (RAPD, ribotyping, tDNA, and ERIC) in determining the genetic diversity of 44 $P$. aeruginosa urinary isolates.

Methods: Performance parameters were analyzed for each of the tested methods. The banding pattern was assessed by calculating polymorphism, genotypic gene diversity and the effective multiplex ratio. Moreover, strain diversity, typeability, and discriminatory power were used to measure the efficiency of typing methods. The congruence among typing methods was calculated by Rand's and Wallace coefficients.

Results: P-640 among RAPD primers and Ribo-2 among ribotyping primers were more informative as they gave high strain diversity, the highest number of clusters, and highest discriminatory power ( $\mathrm{ISD}=70.45 \%, 29$ clusters at $70 \%$ cutoff, $\mathrm{DI}=0.97$ and $\mathrm{ISD}=75 \%, 25$ clusters at $70 \%$ cutoff $\mathrm{DI}=0.969$, respectively). Comparison of typing methods showed that RAPD-PCR gave the highest mean percent polymorphism per assay (76.85\%) followed by ERIC-PCR. ERIC-PCR outperformed in most marker parameters; highest mean number of alleles, number of monomorphic bands per assay unit, mean genotypic gene diversity, effective multiplex ratio, and assay efficiency index. Calculated congruence revealed that individual methods demonstrate moderate to poor predictive power. Interestingly, this power increased by combining data obtained from another method.

Conclusion: RAPD primer (P-640) had more discrimination power followed by ribo- 2 and ERIC. The performance and predictive power of typing methods can be improved by combining data obtained from different methods as ERIC+OPA-02 and ERIC+P-640 combinations gave complete typeability and discrimination of isolates. ERIC, ERIC+OPA-02, and ERIC+P-640 combinations can provide finer discrimination and classification of $P$. aeruginosa strains than the other tested methods.

Keywords: $P$. aeruginosa, PCR-based molecular typing, discrimination power, typeability, congruence

\section{Introduction}

$P$. aeruginosa is a Gram-negative bacillus. It is one of the most important Gramnegative bacteria causing nosocomial infections. In most cases, it is resistant to antibiotics and associated with a high mortality rate. It represents around $10 \%$ of
Correspondence: Dina E Rizk

Microbiology \& Immunology Department Faculty of Pharmacy, Mansoura University, Mansoura, 35516, Egypt

Tel +201002605440

Fax +20502247496

Email dena@mans.edu.eg
Infection and Drug Resistance 2021:14 1019-1035

1019 
urinary tract infections and accounts for about $35 \%$ of mortality due to bacteremia. ${ }^{1,2}$

Bacterial strain typing is significant for diagnosis, treatment, and epidemiological surveillance of bacterial infections. ${ }^{3}$ Bacterial typing can be divided into conventional epidemiological typing and DNA-based typing methods. Conventional epidemiological typing methods include antibiogram, phage typing, and serotyping. ${ }^{4}$ While DNA-based typing methods include many techniques as restriction endonucleases of genomic and plasmid DNA, southern hybridization, pulsed gel electrophoresis (PFGE), PCR-based methods for plasmid and chromosomal profiling, microarray, and the last revolution, wholegenome sequencing. ${ }^{5,6}$

PCR-based typing relies on the amplification of a tiny amount of specific DNA sequence. It includes different methods: PCR-RFLP, PCR-ribotyping, randomly amplified polymorphic DNA (RAPD), repetitive extragenic palindromic (Rep)-PCR, enterobacterial repetitive intergenic consensus (ERIC)-PCR, and PCR sequencing. ${ }^{7}$

RAPD is known as arbitrary primed PCR (AP-PCR) as it amplifies ambiguous regions of the genome. The primers used are short in length (about $10 \mathrm{bp}$ ). The discrimination power of RAPD depends on the number and sequence of the primers used and the amplification conditions. ${ }^{8}$

ERIC-PCR fingerprinting targets highly conserved central inverted repeats of $126 \mathrm{bp}$ located in extragenic regions of bacterial genomes. The position of these regions differs between species and strains, so they are considered genetic markers, ${ }^{5,9}$ ERIC-PCR is an advantageous and fast method; thus it is paralleled with other PCR techniques. ${ }^{6}$

PCR-ribotyping is a technique used to detect polymorphism in intergenic regions of rRNA or tRNA. Intergenic spacer regions (ISRs) are exposed to inferior evolutionary pressure and thus demonstrate broader genetic variations that hang on the number and type of tRNA genes between $23 \mathrm{~S}$ and $16 \mathrm{~S}$ sequences. Two PCRbased methods are used for identifying these ISRs. The first method; PCR-ribotyping which is used for identification and discrimination between bacterial strains and species utilizing primers that amplify the sequences between $16 \mathrm{~S}$ and $23 \mathrm{~S}$ genes. The second technique is tDNA-PCR which amplifies intergenic spacers between tRNA genes. These genes are conserved and present in several copies along the bacterial genome. Besides, they are grouped and disconnected by spacers whose length and sequences are subjected to great variation. ${ }^{10}$
Assessment of the efficiency of the typing method depends on several factors such as typeability and discrimination. Typeability is simply the percentage of bacterial isolates that can be positively typed by the typing marker. ${ }^{11}$ The discriminatory power of a typing method can be estimated by the number of types obtained by this method and their relative frequencies. ${ }^{12}$ It can be expressed by discrimination index (DI) which can be defined as the probability that two random isolates from the test population are distinguished into different typing groups. ${ }^{5,11,12}$

An important characteristic for an ideal marker is high polymorphism with consistent distribution within the genome. In addition, it should give an adequate resolution of genetic differences. The efficiency of molecular markers can be evaluated in assessing genetic diversity by measuring various parameters. The number of total alleles, allele range, \% polymorphism, effective multiplex ratio, assay efficiency index (AEI), and index of strain diversity are performance parameters that can estimate the discriminatory power of the typing methods. ${ }^{13}$ Welsh and McClelland show that comparing polymorphisms in genomic fingerprints can distinguish strains. ${ }^{14}$

The correspondence between typing methods can be assessed quantitatively by calculating two coefficients, Rand (R) and Wallace (W) coefficients. They are used to explore the concordance between typing methods. The value of the $\mathrm{W}$ coefficient indicates the probability that two strains are classified as the same type by either of the two methods. This indicates that results obtained by one method can be predicted by the other method. ${ }^{15}$

The present work aims to compare the efficiency of different PCR-based typing methods (RAPD, ribotyping, tDNA, and ERIC) to discriminate between strains of $P$. aeruginosa isolated from UTIs. Moreover, the concordance of different typing methods and their combinations was evaluated.

\section{Materials and Methods \\ Bacterial Isolates}

Forty-four $P$. aeruginosa isolates were cultured from urine samples obtained from patients at Urology and Nephrology Center, Mansoura University, Egypt.

Isolates were selected based on their colony morphology on Pseudomonas isolation agar (Oxoid). All isolates were confirmed as $P$. aeruginosa using the VITEK 2 system (bioMerieux, Marcy I'Etoile, France) using P. aeruginosa (Schroeter) Migula (ATCC 27853) as 
a quality control strain. Confirmed isolates were stored at $-80^{\circ} \mathrm{C}$ for further studies.

This research was approved by the ethics committee of the faculty of Pharmacy, Mansoura University (code 2020-127). Isolates were a part of the routine hospital laboratory procedure.

\section{Isolation of Bacterial DNA}

Genomic DNA was obtained by the modified boiling method of Englen and Kelley. ${ }^{16}$ Briefly, pure bacterial colonies were mixed with $100 \mu \mathrm{L}$ DNase/RNase-free water and the suspension was held at $95^{\circ} \mathrm{C}$ for $10 \mathrm{~min}$. The lysate was centrifuged and transferred to a new Eppendorf and used as a template DNA.

\section{PCR-Based Typing}

RAPD typing was carried out using six primers: D-10514, ${ }^{17,18}$ D-14306, ${ }^{17}$ OP-13, ${ }^{19,20}$ P-640, ${ }^{16,21}$ OPA-02, ${ }^{22}$ and AP3 ${ }^{23,24}$ PCR ribotyping was done using three sets of universal primers: Ribo-1, ${ }^{25}$ Ribo- $2,{ }^{26}$ and Ribo-3 ${ }^{10}$ ERIC-PCR-reaction was performed using the sequences ERIC1 and ERIC2 $2{ }^{27}$ The tDNA-PCR amplified ISRs between the tRNA genes using the conserved primers $\mathrm{T} 5 \mathrm{~A}$ and $\mathrm{T} 3 \mathrm{~B} .{ }^{10}$ The primers' sequences were illustrated in Table 1. All primers were obtained from Invitrogen (Thermo Scientific). The amplifications were performed in the thermocycler machine (Model TC96K, AccuLab $^{\circledR}$, USA). The temperature profile and the PCR conditions were conducted as described previously for each primer. The PCR products of all typing methods were electrophoresed in 1.5\% agarose gel with the DNA molecular weight marker (GeneRuler 100 bp Plus DNA Ladder, Thermo Scientific) and visualized in a gel documentation system (Model Gel Doc 1.4, 1189; AccuLab ${ }^{\circledR}$ ). DNA fingerprints were recorded and compared visually.

\section{Data Analysis}

For data analysis, each band with a different size was assigned and marked by a binary system ( 1 for presence and 0 for the absence of band of a specific molecular weight). The banding patterns produced by the different tested markers were analyzed by constructing a dendrogram using the unweighted pair group method with arithmetic mean (UPGMA) to determine the relatedness between isolates using the Dice coefficient, with the program DendoUPGMA [Univertat Rovirai Virgili (URV), Tarragona, Spain].

The polymorphism percentage (PM\%), monomorphism percentage (MM\%) were calculated for each typing system. ${ }^{28}$ Genotypic gene diversity $\left(\mathrm{H}_{\mathrm{g}}\right)$ was calculated as described earlier ${ }^{28,29}$ by the following equation:

$$
\mathrm{H}_{\mathrm{g}}=1-\left(\mathrm{pi}^{2}-\mathrm{qi}^{2}\right)
$$

where pi (pi $=1$-qi) refers to the frequency of the dominant allele and qi represents the frequency of the null allele (ie the number of isolates without the band).

Table I Sequence of the Primers Used in This Study

\begin{tabular}{|c|c|c|c|}
\hline \multicolumn{2}{|c|}{ Primer Name } & Nucleotide Sequence ( 5 to $3^{\prime}$ ) & References \\
\hline RAPD & $\begin{array}{l}\text { D- } 10514 \\
\text { D- } 14306 \\
\text { OPA13 } \\
\text { P-640 } \\
\text { OPA-02 } \\
\text { AP3 }\end{array}$ & $\begin{array}{l}\left(5^{\prime} \text {-TGGTGGCCTCGAGCAAGAGAACAAAG-3') }\right. \\
\left(5^{\prime} \text {-GGTTGGGTGAGAATTGC-3') }\right. \\
\left(5^{\prime}-\text { CAGCACCCAC-3') }\right. \\
\left(5^{\prime} \text {-CGTGGGGCCT-3') }\right. \\
\left(5^{\prime}-\text { TGCCGAGCTG-3') }\right. \\
\left(5^{\prime} \text {-TCA CGA TGC A-3') }\right.\end{array}$ & $\begin{array}{l}{[17,18]} \\
{[17]} \\
{[19,20]} \\
{[16,21]} \\
{[22]} \\
{[23,24]}\end{array}$ \\
\hline Ribotyping & $\begin{array}{l}\text { Ribo-I } \\
\text { Ribo-2 } \\
\text { Ribo-3 }\end{array}$ & $\begin{array}{l}\text { Fw }\left(5^{\prime} \text {-TTGTACACACCGCCCGTCA-3') }\right. \\
\operatorname{Rv}\left(5^{\prime}-\text { GGTACCTTAGATGTTTCAGTTC-3') }\right. \\
\text { Fw (5'-GAAGTCGTAACAAGG-3') } \\
\operatorname{Rv}\left(5^{\prime} \text {-CAAGGCATCCACCGT-3') }\right. \\
\text { Fw (5'-TTGTACACACCGCCCGTCA-3') } \\
\operatorname{Rv}\left(5^{\prime} \text {-GGTACCTTAGATTGTTTCAGTTC-3') }\right.\end{array}$ & $\begin{array}{l}{[25]} \\
{[26]} \\
{[10]}\end{array}$ \\
\hline ERIC & & $\begin{array}{l}\text { Fw (5'- ATGTAAGCTCCTGGGGATTCAC-3') } \\
\operatorname{Rv}\left(5^{\prime} \text {-AAGTAAGTGACTGGGGTGAGCG-3') }\right.\end{array}$ & {$[27]$} \\
\hline tDNA & & $\begin{array}{l}\text { Fw (5'-AGTCCGGTGCTCTAACCAACTGAC-3') } \\
\operatorname{Rv}\left(5^{\prime} \text {-AGGTCGCGGGTTCGAATCC-3') }\right.\end{array}$ & {$[10]$} \\
\hline
\end{tabular}

Abbreviations: Fw, forward; Rv, reverse. 
The effective Multiplex Ratio (EMR) is the product of the fraction of polymorphic bands and the number of polymorphic bands for an individual assay where $n_{p}$ is the number of polymorphic bands and $\mathrm{n}$ is the total number of bands. It was calculated according to the equation: ${ }^{28}$

$$
\operatorname{EMR}(E)=n_{p}\left(n_{p} / n\right)
$$

In addition, the assay efficiency index (AEI $=$ Polymorphic bands/Total number of primers $)^{28}$ of each typing method was calculated.

To determine the index of strain diversity (ISD), that measured as the frequency of diverse genotypes, the following equation was used. ${ }^{30}$

$$
\operatorname{ISD}(\%)=100 \% \text { (number of geno types/total number of isolates) }
$$

The typeability of each typing method was calculated as the percentage of isolates that can be typed among the tested ones. $^{13,31}$ For the discriminatory power of each typing method, it was assessed by calculating the discriminatory index (DI) according to the following Simpson's equation: ${ }^{31}$

$$
\mathrm{DI}=1-[1 / \mathrm{N}(\mathrm{N}-1)] \sum_{j=1}^{s} \mathrm{n}_{\mathrm{j}}\left(\mathrm{n}_{\mathrm{j}}-1\right)
$$

Where N: the total number of isolates, $\mathrm{S}$ : the total number of types, $n_{j}$ : the number of isolates belonging to the $\mathrm{jth}$ type, and Non-typeable isolates were gathered into one group (untypeable group).

Calculation of the concordance of different typing methods and their combinations was done by the software described by Carrico et $\mathrm{al}^{32}$ where Rand's (R) and adjusted Wallace's coefficients (W) were calculated.

\section{Results}

In the present study, the genetic diversity of 44 P. aeruginosa isolates was assessed using RAPD, ribotyping, tDNA, and ERIC typing techniques. The banding patterns were scored and were designed by a numeral for each primer.

\section{RAPD Analysis}

Among the 44 tested isolates, the typeability ranged from $70.5 \%$ to $97.7 \%$ (Table 2). RAPD-PCR typed 43 isolates by primer D-14306 and OP-13 (typeability 97.7\%). Thirteen isolates were untypable by AP3 primer (typeability $70.5 \%$ ). P-640 primer gave the highest strain diversity (ISD $=70.45 \%$ ), while $\mathrm{D}-14306$ was the least marker in differentiating isolates ( $\mathrm{ISD}=29.54 \%$ ).

Amplification using primer D-10514 yielded 27 genotypes through amplifying 15 bands ranging from $150 \mathrm{bp}$ to $2000 \mathrm{bp}$. It clustered the isolates into 22 clusters at $67 \%$ cutoff. At cutoff $72 \%$, two clusters could be further subdivided into two groups. One of these clusters was subdivided into three groups at $77 \%$ cutoff and into four groups at $80 \%$ cutoff. Six clusters were found to contain isolates with $100 \%$ similarity (Figure $1 \mathrm{~A}$ ).

Primer D-14306 generated 13 genotypes by amplifying 10 bands ranging approximately from $500 \mathrm{bp}$ to $2000 \mathrm{bp}$. It classified the isolates into 7 clusters at $70 \%$ cutoff where they grouped them into 10 clusters at $83 \%$ cutoff, 12 clusters at $90 \%$ cutoff, and 13 clusters at $97 \%$ cutoff. Cluster No. one comprised the highest number of isolates (27) with $100 \%$ similarity. Three isolates were different at all levels of similarity (Figure 1B).

Table 2 Typeability, Index of Strain Diversity, and Cluster Analysis of 44 P. aeruginosa Strains Using Different PCR-Based Typing Methods

\begin{tabular}{|l|c|c|c|c|c|c|}
\hline \multicolumn{2}{|l|}{ Typing Method } & Typeability (\%) & ISD(\%) & No. of Clusters & Cutoff & No. of Clusters at 70\% Cutoff \\
\hline RAPD-PCR genotyping & D-105 I4 & 90.9 & 61.36 & 22 & $67 \%$ & 23 \\
& D-14306 & 97.7 & 29.54 & 7 & $70 \%$ & 7 \\
& OP-13 & 97.7 & 56.81 & 19 & $62 \%$ & 23 \\
& OPA-02 & 81.8 & 40.90 & 10 & $65 \%$ & 13 \\
& P-640 & 86.4 & 70.45 & 27 & $65 \%$ & 29 \\
& AP3 & 70.5 & 59.09 & 25 & $70 \%$ & 25 \\
\hline \multirow{2}{*}{ Ribotyping } & Ribo-I & 97.7 & 18.18 & 8 & $97 \%$ & 8 \\
& Ribo-2 & 97.7 & 75.00 & 19 & $60 \%$ & 10 \\
\hline tDNA-PCR & Ribo-3 & 100 & 29.54 & 10 & $75 \%$ & 18 \\
\hline ERIC-PCR & 97.7 & 47.72 & 15 & $65 \%$ & 28 \\
\hline
\end{tabular}

Abbreviation: ISD, index of strain diversity. 

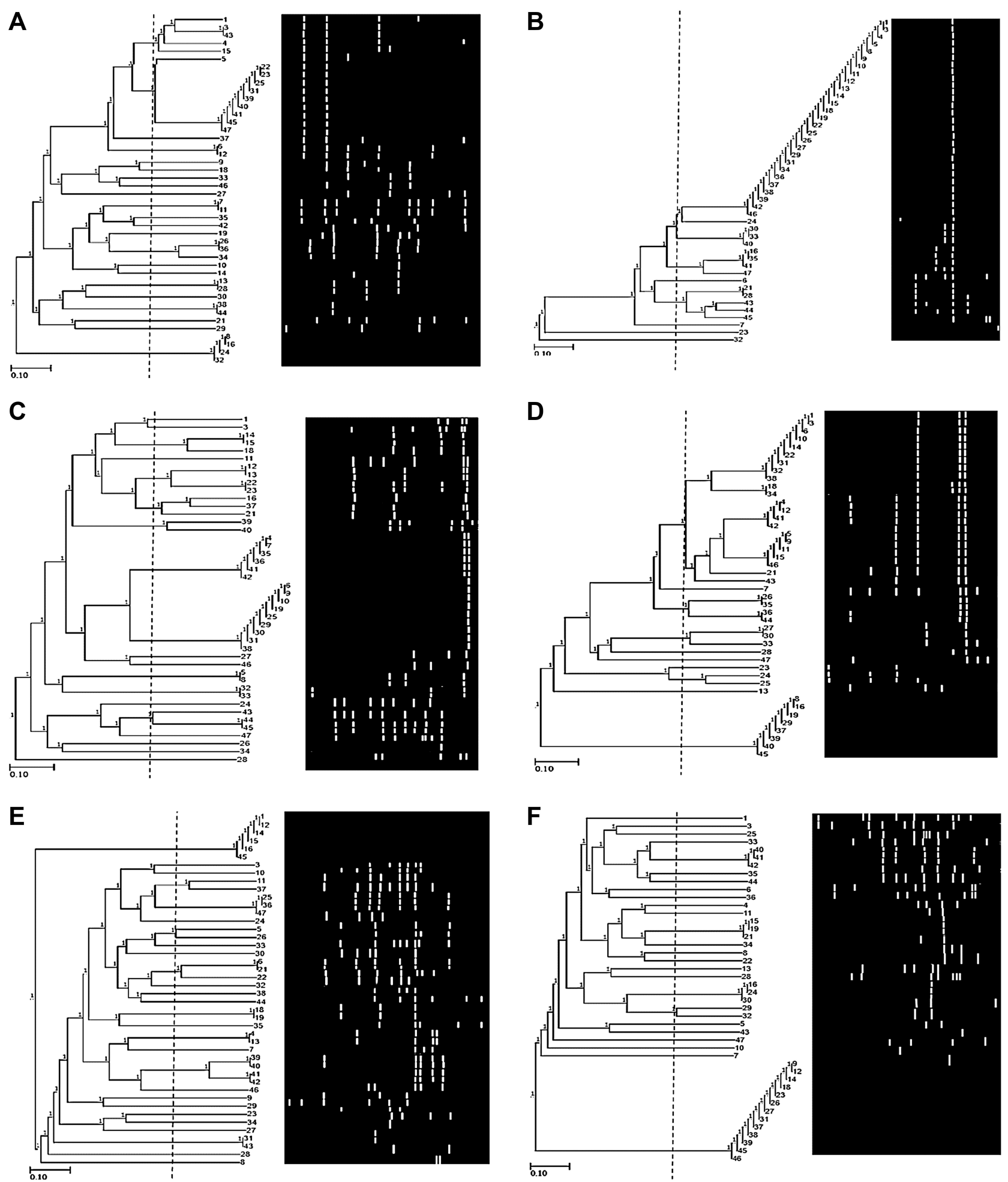

Figure I Dendrogram of 44 P. aeruginosa isolates using UPGMA algorithm and Dice coefficient for D-105I4 primer (A), D-I4603 primer (B), OP-I3 primer (C), OPA-02 primer(D), P-640 primer (E), and AP3 (F). Patterns are schematically represented.

OP-13 and OPA-02 primers generated 25 genotypes (22 different bands ranging from $300 \mathrm{bp}$ to $2500 \mathrm{bp}$ ) and 18 genotypes (12 bands ranging from $300 \mathrm{bp}$ to $2500 \mathrm{bp}$ ), respectively (Figure 1C and D). The isolates were classified by OP-13 into 19 clusters at $62 \%$ cutoff where they were grouped into 25 clusters at $97 \%$ cutoff. Eight Clusters showed 100\% similarity between their isolates. On the other hand, OPA-02 classified the 
isolates into $10,14,17$, and 18 clusters at $65 \%, 76 \%$, $83 \%$ and $97 \%$ cutoff, respectively. Eight Clusters showed $100 \%$ similarity between their isolates.

Thirty-one different genotypes were obtained by P-640 primer by amplifying 24 bands ranging from $250 \mathrm{bp}$ to $>3000$ bp. P-640 primer classified the isolates into 27 clusters at $65 \%$ cutoff where they grouped them into 31 clusters at $97 \%$ cutoff where four clusters were further subdivided each into two groups. Eight clusters showed $100 \%$ similarity between their isolates with cluster No. 1 comprised six isolates (Figure 1E).

AP3 primer gave 26 genotypes with band sizes ranging between $250 \mathrm{bp}$ and $3000 \mathrm{bp}$ ( 25 bands). The isolates could be clustered into 25 clusters with two isolates showing similarity at $70 \%$ cutoff. Isolates $(40,41$ and 42$),(15,19$ and 21) and (16, 24 and 30) showed 100\% similarity. Cluster No. 25 comprises the highest number of isolates (Figure 1F).

The number of the obtained amplicons in all tested isolates was specific for each of the tested RAPD primers. All tested primers showed PM\% ranged between $70 \%$ to $86.7 \%$. A number of 82 out of 108 total alleles was polymorphic. AP3 generated a maximum of 25 alleles followed by P-640 primer with 24 alleles. D-14306 generated a minimum of 10 alleles (Table 3).

The calculated EMR ranged between 4.9 and 14.44 (mean EMR=10.44). Gene diversity $\left(H_{g}\right)$ values ranged between 0.3 and 1.36 with an average of 0.97 . A total of 770 amplicons were observed and AEI was 13.67. D-14306 primer revealed minimum values of $\mathrm{H}_{\mathrm{g}}$ and EMR (Table 3).

\section{PCR Ribotyping}

The ribotyping assay was performed using three different markers. Both Ribo-1 and Ribo-2 primers typed 43 out of 44 tested isolates (typeability 97.7\%). Ribo-3 primer typed all isolates resulting in 100\% typeability (Table 2 ).

Ribo-1 primer distinguished the typable isolates within eight genotypes ( $\mathrm{ISD}=18.18 \%$ ) through amplifying eight bands (500bp to $2000 \mathrm{bp}$ ) (Figure 2A). Ribo-2 primer amplified 20 visible bands (200bp to $2000 \mathrm{bp}$ ) resulting in 33 genotypes with high ISD $=75.00 \%$ (Figure $2 \mathrm{~B}$ ). The third primer (Ribo-3) classified the tested isolates into 13 distinct genotypes with $\mathrm{ISD}=29.54 \%$ by amplifying 10 different DNA fragments ranging approximately from 100 bp to 1500 bp (Figure 2C).

Ribo-1 primer showed the highest similarity between isolates where it classified them into 7 clusters at $97 \%$ cutoff. Cluster No. 2 contained 23 (52.27\%) isolates. Ribo-2 primer classified the isolates into 19 clusters at $60 \%$ cutoff while it grouped them into 30 clusters at $80 \%$ cutoff where 3 clusters were further subdivided into two groups and four clusters were subdivided into 3 groups. At 97\% cutoff, 32 clusters were found, five of them contained isolates with $100 \%$ similarity. Ribo-3 primer classified the isolates into 10 clusters at $70 \%$ cutoff and 13 clusters at $97 \%$ cutoff where 3 clusters

Table 3 Polymorphism Detected by the Used PCR-Based Typing Primers

\begin{tabular}{|c|c|c|c|c|c|c|c|c|c|c|}
\hline Typing Method & Total Alleles & MB & PB & MM\% & PM\% & Total Amplicons & Allele Range & $\mathbf{H}_{\mathbf{g}}$ & EMR & AEI \\
\hline \multicolumn{11}{|c|}{ RAPD-PCR genotyping } \\
\hline D-105I 4 & 15 & 2 & 13 & 13.3 & 86.7 & 135 & $150-2000$ & 1.36 & 11.27 & 13.67 \\
\hline D-14306 & 10 & 3 & 7 & 30 & 70 & 68 & $500-2000$ & 0.30 & 4.9 & \\
\hline OP-13 & 22 & 6 & 16 & 27.3 & 72.7 & 148 & $300-2500$ & 1.14 & 11.64 & \\
\hline OPA-02 & 12 & 2 & 10 & 16.7 & 83.3 & 127 & $300-2500$ & 0.58 & 8.33 & \\
\hline P-640 & 24 & 7 & 17 & 29.2 & 70.8 & 173 & $250->3000$ & 1.12 & 12.04 & \\
\hline AP3 & 25 & 6 & 19 & 24 & 76 & 119 & $250-3000$ & 1.30 & 14.44 & \\
\hline \multicolumn{11}{|l|}{ Ribotyping } \\
\hline Ribo-I & 8 & 2 & 6 & 25 & 75 & 83 & $500-2000$ & 0.30 & 4.5 & 9.3 \\
\hline Ribo-2 & 20 & 6 & 14 & 30 & 70 & $17 \mid$ & $200-2000$ & 0.53 & 9.8 & \\
\hline Ribo-3 & 10 & 2 & 8 & 20 & 80 & 105 & $100-1500$ & 0.30 & 6.40 & \\
\hline tDNA-PCR & 16 & 5 & 11 & 31.3 & 68.7 & 120 & $100-3000$ & 0.68 & 7.56 & 11 \\
\hline ERIC-PCR & 21 & 6 & 15 & 28.6 & 71.4 & 149 & $200-3000$ & 1.41 & 10.71 & 15 \\
\hline
\end{tabular}

Abbreviations: PB, number of monomorphic bands; PB, number of polymorphic bands; $M M$ (\%), monomorphism percentage; $\mathrm{PM}$ (\%), polymorphism percentage; $\mathrm{H}_{\mathrm{g}}$, genotypic gene diversity; EMR, effective multiplex ratio; AEl, assay efficiency index. 

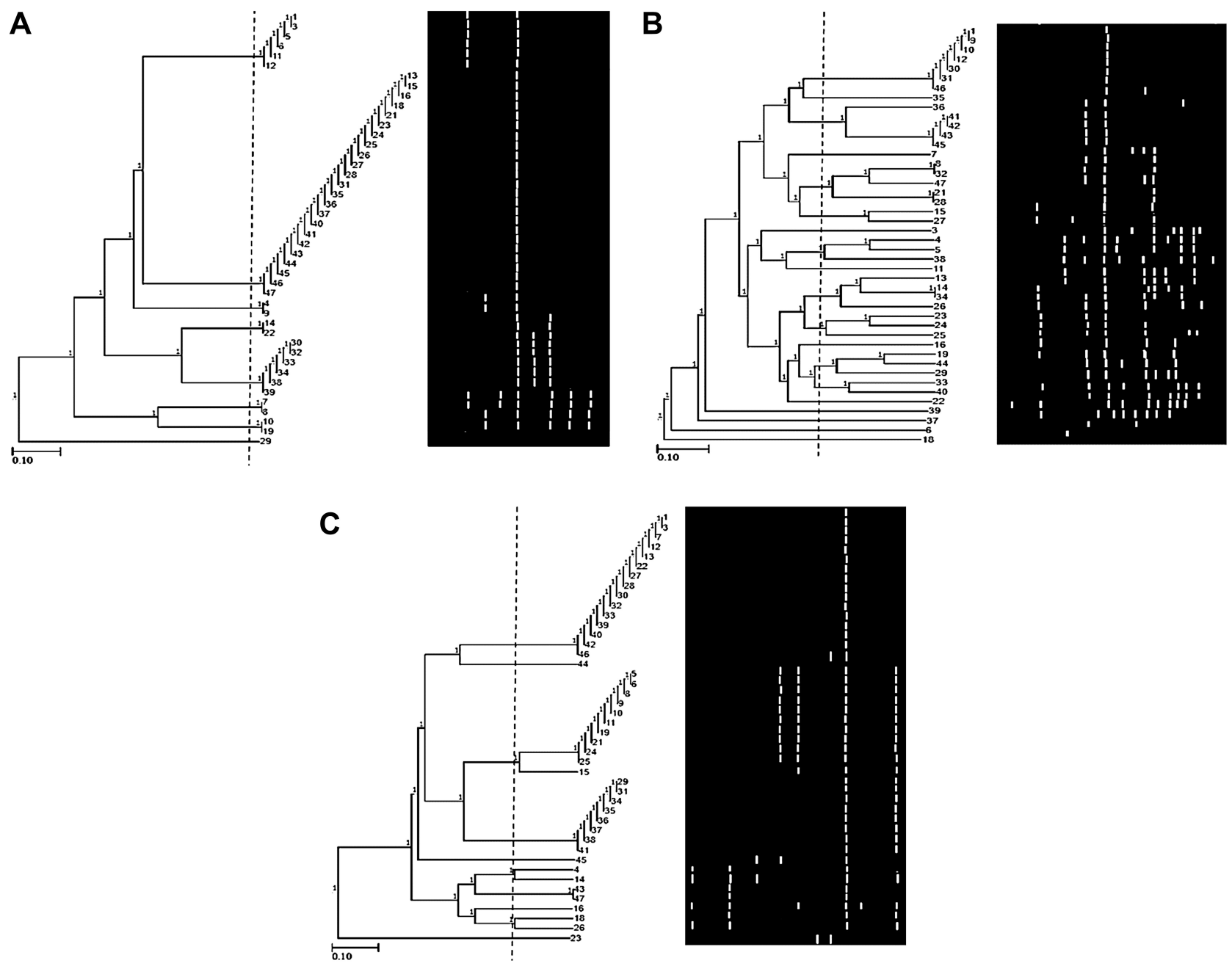

Figure 2 Dendrogram of 44 P. aeruginosa isolates using UPGMA algorithm and Dice coefficient for Ribo-I primer (A), Ribo-2 primer (B), and Ribo-3 primer (C). Patterns are schematically represented.

were further subdivided into two groups. Isolates of four clusters showed $100 \%$ similarity.

Ribotyping revealed a total of 38 alleles, with an average of 12.67 per primer. Twenty-eight alleles were polymorphic resulting in an average of $75 \%$ polymorphism. The maximum $\mathrm{H}_{\mathrm{g}}$ and EMR were observed with the primer Ribo-2. A total of 359 amplicons were obtained by ribotyping primers and AEI was 9.3 as illustrated in Table 3.

\section{tDNA-PCR}

tDNA marker typed $97.7 \%$ of isolates. It demonstrated 21 different genotypes with moderate strain diversity (ISD= $47.72 \%$ ) of isolates by amplifying 16 alleles that ranged from $100 \mathrm{bp}$ to $3000 \mathrm{bp}$. Among the tested isolates, tDNA amplified 120 amplicons, AEI was 11. The $\mathrm{H}_{\mathrm{g}}$ and EMR values were 0.68 and 7.56, respectively (Table 3 ).

tDNA primer classified the isolates into 15 clusters at $65 \%$ cutoff where they grouped them into 18 clusters at
$75 \%$ cutoff and 20 clusters at $97 \%$ cutoff. Isolates of seven clusters showed 100\% similarity (Figure 3A).

\section{ERIC-PCR}

The molecular typing using ERIC-PCR generated 21 different alleles (200 bp to $3000 \mathrm{bp}$ ) among the 36 typed isolates (Figure 3B), 81.8\% typeability (Table 2). Six bands were monomorphic and 15 were polymorphic. The typable isolates were classified into 32 genotypes with $\mathrm{ISD}=72.72 \%$. Besides that, EMR was 15.43 . A total of 149 amplicons were observed and AEI was 18 (Table 3).

ERIC primer clustered the isolates into 28 clusters at $75 \%$ cutoff. Two clusters (No. 3 and 7) could be further subdivided into two and three groups at $87 \%$ cutoff, respectively. There was $100 \%$ similarity between isolates (24 and 25), (9, 10 and 43), (15 and 18), and (11, 22 and 29). Cluster No.28 contains the highest number (8) of isolates with $97 \%$ similarity. 
A

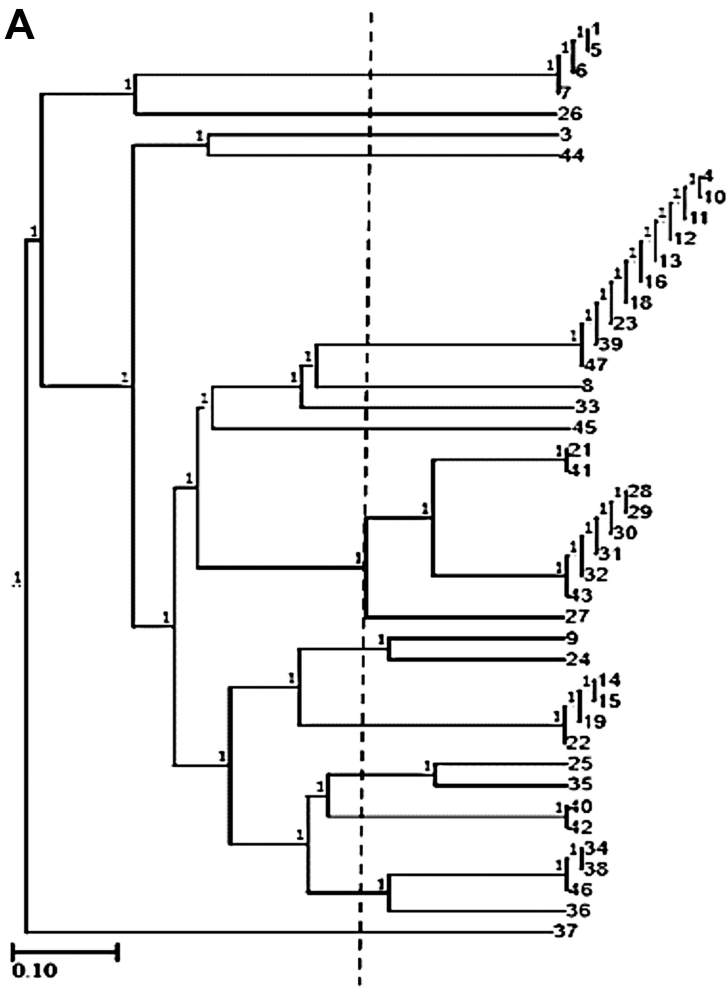

B

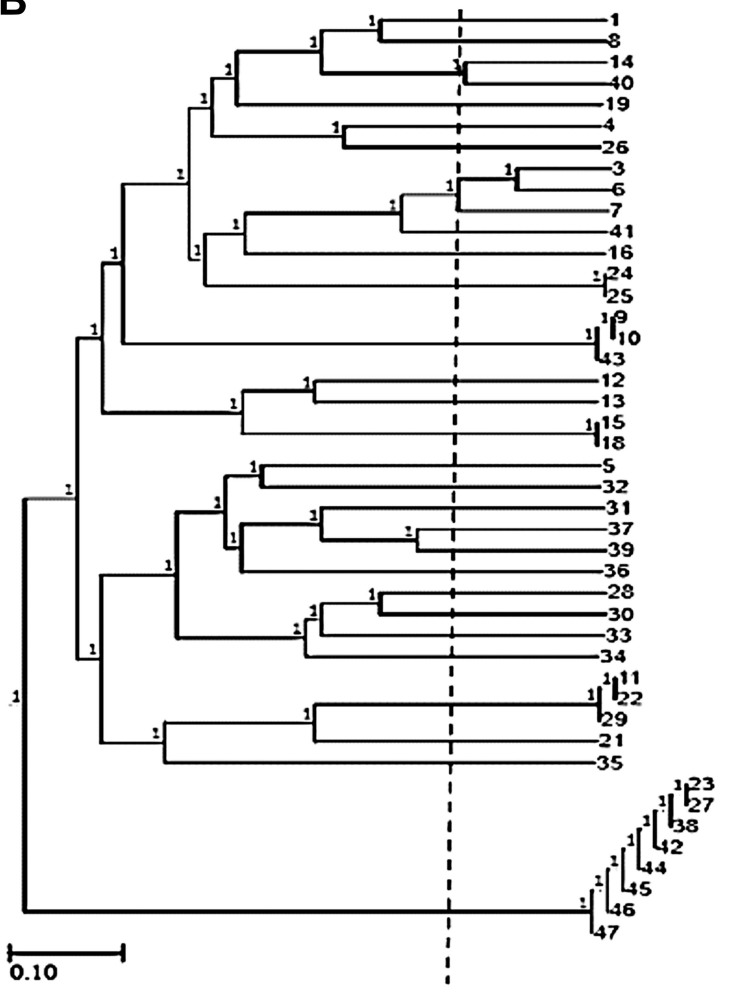

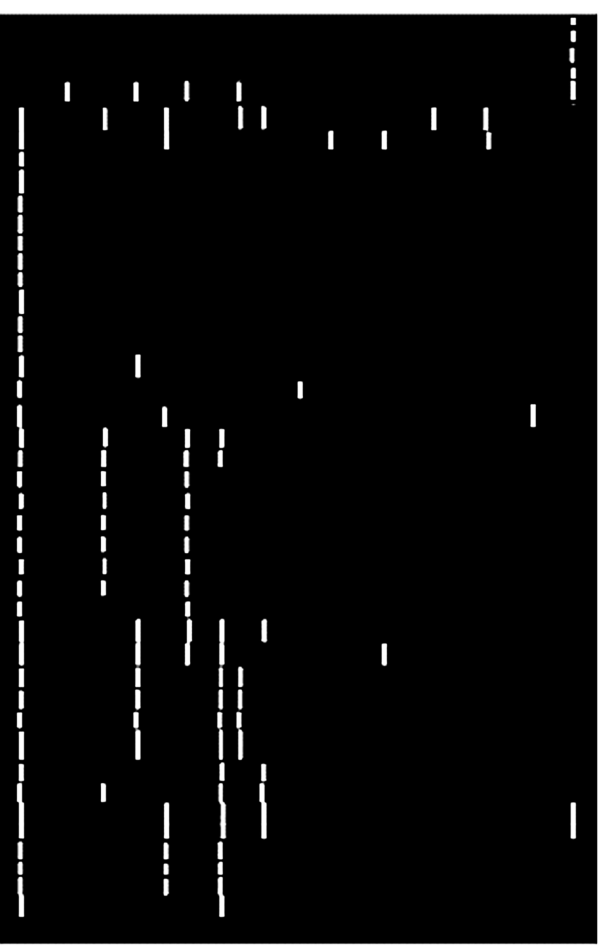

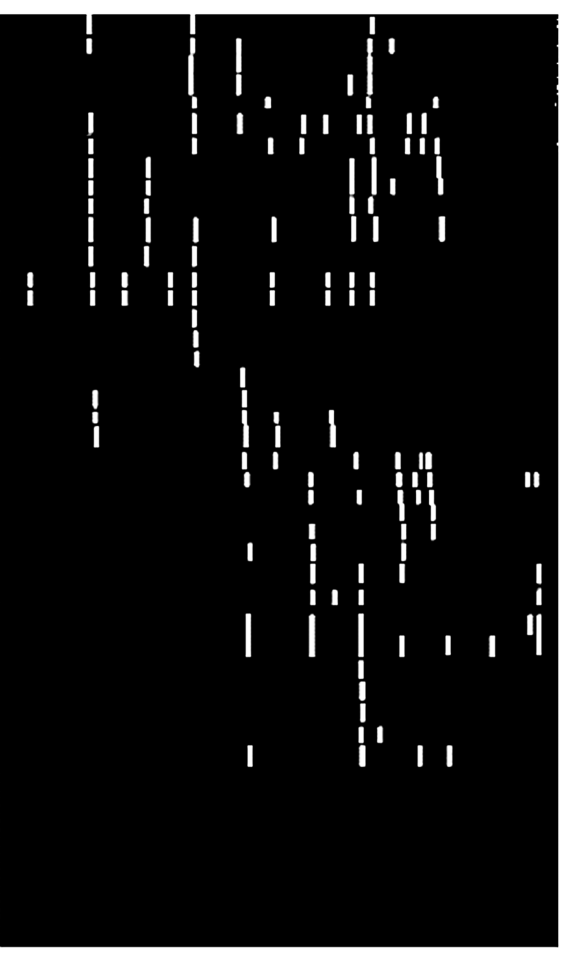

Figure 3 Dendrogram of 44 P. aeruginosa isolates using the UPGMA algorithm and Dice coefficient for tDNA-PCR typing (A) and ERIC-PCR typing (B). Patterns are schematically represented. 


\section{Comparative Analysis of Banding Genotypes Generated by Typing Systems}

ERIC marker system showed superior values of the mean number of alleles per assay unit, the number of monomorphic and polymorphic bands per assay unit (21, 6, and 15, respectively) as shown in Table 4. Despite that, a higher percentage of polymorphism was obtained from RAPD analysis $(76.85 \%)$ as compared to ERIC (71.4\%). Moreover, ERIC showed higher values of mean genotypic gene diversity (1.41), EMR (10.71), and AEI (15) followed by RAPD marker system accounting $0.97,10.44$, and 13.67, respectively. The Ribotyping system showed the lowest values of marker parameters; mean number of alleles per assay unit (12.67), number of monomorphic (3.33), and polymorphic bands (9.33) per assay unit, mean genotypic gene diversity (0.38), EMR (6.9). tDNA marker system showed the lowest mean percentage of polymorphism per assay (68.7\%) and AEI (11).

\section{Discriminatory Power and Concordance Among Typing Systems}

Concerning the discriminatory power, Table 5 shows the discriminatory indices (DIs)of the typing methods using

Table 4 Comparative Analysis of Banding Genotypes Generated by the Four PCR-Typing Techniques

\begin{tabular}{|l|c|c|c|c|}
\hline Components & RAPD & Ribotyping & tDNA & ERIC \\
\hline Number of assay units & 6 & 3 & 1 & 1 \\
\hline Total amplicons & 770 & 359 & 120 & 149 \\
\hline Total No. of alleles & 108 & 38 & 16 & 21 \\
\hline $\begin{array}{l}\text { Mean No. of alleles per } \\
\text { assay unit }\end{array}$ & 18 & 12.67 & 16 & 21 \\
\hline $\begin{array}{l}\text { Number of } \\
\text { monomorphic bands } \\
\text { per assay unit }\end{array}$ & 4.33 & 3.33 & 5 & 6 \\
\hline $\begin{array}{l}\text { No of polymorphic } \\
\text { bands per assay unit }\end{array}$ & 13.83 & 9.33 & 11.00 & 15.00 \\
\hline $\begin{array}{l}\text { Mean (\%) } \\
\text { polymorphism per assay }\end{array}$ & 76.85 & 75 & 68.7 & 71.4 \\
\hline $\begin{array}{l}\text { Mean genotypic gene } \\
\text { diversity }\end{array}$ & 0.97 & 0.38 & 0.68 & 1.41 \\
\hline $\begin{array}{l}\text { Effective multiplex ratio } \\
\text { Assay efficiency index }\end{array}$ & 10.44 & 6.9 & 7.56 & 10.71 \\
\hline
\end{tabular}

each primer and those of the combination of the methods. The DIs ranged from 0.622 to 0.975 . Three primers (P-640, Ribo-2, ERIC) gave DI above the recommended value, 0.95 . The highest DI value (0.975) was obtained by using a P-640 primer. The DIs for D-10514 and OP-13 primers were 0.949 and 0.94 , respectively. The lowest DI was 0.622 of D-14306 primer, showing poor discriminatory power (Table 5 ).

The combination of different typing methods noticeably increases the DI values. ERIC highly increases the DI of all typing methods, DI of 1 was achieved with OP-O2 $+\mathrm{P}-640$ pair. Also, all ribotyping primers and tDNA increased the DI with the combined typing methods. D-14306 primer that gave the lowest DI alone, revealed higher DI in all combination pairs.

The highest concordance was found between RAPD typing using P-640 primer and ribotyping using Ribo-2 primer calculated by Rand's coefficient $(\mathrm{R}=0.948)$ (Table 6). Both ERIC and ribotyping using Ribo-2 primer gave high concordance with all typing methods $(\mathrm{R}=0.607-0.939$ and 0.627-0.948, respectively). Only D-14306 and Ribo1-types which were moderately predicted by AP3 and ERIC using Wallace coefficient ( $\mathrm{W}=0.427$ and 0.536 ) with a $95 \%$ confidence level (CI), respectively. The other types of all typing methods were poorly predicted by either of these methods (Table 7).

For combinations of typing methods, it was found that concordance highly increased as indicated by the Rand coefficient for all combined pairs. Complete concordance was found between the ERIC+ OPA-O2 pair using the $\mathrm{ERIC}+\mathrm{P}-640$ pair $(\mathrm{R}=1)$. Increased concordance $(\mathrm{R}=0.998)$ was found using tDNA+D-10514 and tDNA +Ribo-2 with tDNA+ERIC, $\mathrm{R}=0.979$ using Ribo-1+OPA02 with Ribo-1+P-640, $\mathrm{R}=0.998$ in Ribo-2+D-10514 with Ribo-2+ERIC and $\mathrm{R}=0.993$ in Ribo-3+D-10514 with Ribo-3+P-640 and Ribo-3+P-640 with Ribo-3+ERIC (data not shown).

Additionally, ERIC + OPA-02 and ERIC $+\mathrm{P}-640$ pairs were able to predict the types produced by all other combination pairs with ERIC (W=1). ERIC+Ribo-1 could be completely predicted by either ERIC+OP-13 or ERIC + tDNA (W= 1) (Table 8). Moreover, tDNA+D-10514 and tDNA+Ribo-1 were predicted completely with tDNA +ERIC. Ribo-2+D-14306 was highly predicted by Ribo-2 +OPA-02 and Ribo-2+AP3 with $\mathrm{W}=0.797$ and 0.855 , respectively. Besides, Ribo-3+D-14306 was best predicted by Ribo-3+AP3 and Ribo-3+ERIC with $\mathrm{W}=0.802$ and 0.728 , respectively (data not shown). 
Table 5 The Discriminatory Power of the Typing Methods, Apart and in Combination, Evaluated with 44 P. aeruginosa Strains

\begin{tabular}{|c|c|c|c|c|c|c|c|c|c|c|c|c|}
\hline \multirow[t]{3}{*}{ Methods } & \multirow{3}{*}{$\begin{array}{l}\text { No. of } \\
\text { Types }\end{array}$} & \multirow[t]{3}{*}{ DI } & \multirow{2}{*}{\multicolumn{2}{|c|}{$\begin{array}{c}\text { ERIC } \\
\text { Combinations }\end{array}$}} & \multicolumn{6}{|c|}{ Ribotyping Combinations } & \multirow{2}{*}{\multicolumn{2}{|c|}{$\begin{array}{c}\text { t-DNA } \\
\text { Combinations }\end{array}$}} \\
\hline & & & & & \multicolumn{2}{|c|}{ Ribo-I } & \multicolumn{2}{|c|}{ Ribo-2 } & \multicolumn{2}{|c|}{ Ribo-3 } & & \\
\hline & & & $\begin{array}{l}\text { No. of } \\
\text { Types }\end{array}$ & DI & $\begin{array}{l}\text { No. of } \\
\text { Types }\end{array}$ & DI & $\begin{array}{l}\text { No. of } \\
\text { Types }\end{array}$ & DI & $\begin{array}{l}\text { No. of } \\
\text { Types }\end{array}$ & DI & $\begin{array}{l}\text { No. of } \\
\text { Types }\end{array}$ & DI \\
\hline D-14306 & 13 & 0.622 & 38 & 0.989 & 22 & 0.930 & 38 & 0.983 & 22 & 0.920 & 32 & 0.968 \\
\hline$D-10514$ & 27 & 0.949 & 41 & 0.996 & 35 & 0.980 & 43 & 0.999 & 39 & 0.994 & 42 & 0.997 \\
\hline OP-13 & 25 & 0.940 & 43 & 0.999 & 37 & 0.989 & 40 & 0.993 & 32 & 0.979 & 40 & 0.995 \\
\hline OP-O2 & 18 & 0.911 & 44 & 1.000 & 32 & 0.983 & 40 & 0.995 & 32 & 0.983 & 39 & 0.995 \\
\hline P-640 & 31 & 0.975 & 44 & 1.000 & 38 & 0.992 & 42 & 0.998 & $4 I$ & 0.997 & 40 & 0.996 \\
\hline AP3 & 26 & 0.908 & 40 & 0.989 & 33 & 0.971 & 40 & 0.993 & 37 & 0.988 & 39 & 0.992 \\
\hline Ribo-I & 8 & 0.697 & 36 & 0.976 & 31 & 0.978 & & & & & & \\
\hline Ribo-2 & 33 & 0.969 & 43 & 0.999 & 42 & 0.998 & & & & & & \\
\hline Ribo-3 & 13 & 0.811 & 41 & 0.996 & 35 & 0.988 & & & & & & \\
\hline $\mathrm{t}-\mathrm{DNA}$ & 21 & 0.921 & 43 & 0.999 & & & & & & & & \\
\hline ERIC & 32 & 0.964 & & & & & & & & & & \\
\hline
\end{tabular}

\section{Discussion}

Several techniques have been used to evaluate the genetic diversity of $P$. aeruginosa including PFGE which is the genotypic characteristics gold standard tool, primed PCR, ribotyping, multilocus sequence typing (MLST), and ERIC-PCR. PCR-based typing represents a simple and fast method for typing as compared to PFGE. Their discrimination power may be equivalent to $\mathrm{PFGE}{ }^{27}$

To the best of our knowledge, this is the first study that represents the most extensive evaluation of RAPD, ribotyping, tDNA, and ERIC to assess the relative strengths and weaknesses of each method or their combinations in discrimination of $P$. aeruginosa isolates from UTIs. In this study, we analyzed $44 P$. aeruginosa isolates to quantify the performance characteristics and congruence between the studied methods.

RAPD is used to detect the genetic diversity by using a short oligonucleotide random sequence to arbitrarily amplify segments of target DNA. ${ }^{3}$ Six primers of RAPD were used for the molecular characterization of $P$. aeruginosa isolates. All primers gave $\geq 10$ alleles indicating good resolving power. It was observed that primers, D-10514 and OPA-02, gave the higher PM\% (86.7\% and $83.3 \%$, respectively) with the allele range of $150-2000$ and 300-2500 bp, respectively. The mean number of alleles, number of polymorphic and monomorphic bands per unit for the RAPD typing method were 18, 13.83, and 4.33, respectively besides a high EMR of 10.68. In addition, the mean (\%) polymorphism was 76.85 . The monomorphic bands among strains illustrated the conserved regions in the genome. ${ }^{33}$ In contrast, Pethannan et al found that all RADP primers used for typing Pseudomonas species produced polymorphic bands and no monomorphic bands were detected. ${ }^{34}$ Comparison between the six RAPD markers revealed that no individual marker achieved both high typeability and discrimination. When measuring the efficacy of the markers according to DI, P-640 primer was the best marker as it showed the highest DI value (0.975) where it classified the 44 isolates into 31 genotypes with ISD $=70.45 \%$. While when assessing these markers according to typeability, D-14306 and OP-13 markers recorded $97.7 \%$ as only one isolate was non-typeable by each marker. Evaluating the efficacy of the markers in measuring the similarities between isolates illustrated that the D-14306 marker was the best as its ISD $=29.54 \%$. Moreover, it classified the isolates into 7 clusters at $70 \%$ cutoff, 13 clusters at $97 \%$ cutoff, and 4 clusters enclosed $79.54 \%$ of isolates at $100 \%$ cutoff.

Three ribotyping markers were included in the present study. On using Ribo-1 primer, 23 (52.27\%) isolates have the same genotype No. 1 while the other 20 isolates were distributed over seven ribotypes with $\mathrm{DI}=0.697$. These results indicate that these isolates may originate from the same source, besides that it demonstrated the constancy of the ISRs of these isolates. ${ }^{35}$ This may be also explained by the limited number of bands in each ribotype that did not give sufficient differentiation. However, Satpathy et al showed that Ribo-1 classified P. aeruginosa isolates into 
four ribotypes with $\mathrm{DI}=0.91 .^{25}$ For the Ribo- 2 primer, genotype No. 2 was predominant with seven (15.90\%) isolates while for Ribo-3, out of the 13 genotypes generated, genotypes No. 1 and 3 consist of 15 (34.09\%) and 10 $(22.72 \%)$ isolates, respectively. Wolska and Szweda also reported that ribotyping of $62 P$. aeruginosa isolates resulted in 9 groups with $80 \%$ of isolates being in two groups. $^{26}$ Spacov et al reported that Ribo-3 generated 8 types with $79 \%$ of isolates classified as one type. ${ }^{10}$ rRNA genetic loci of prokaryotes have three types of genes (16S, $23 \mathrm{~S}$, and $5 \mathrm{~S}$ ) that are separated by spacer regions with diverse lengths and sequences in the genus and species. The spacer region between $16 \mathrm{~S}$ and $23 \mathrm{~S}$ can be used for the identification of bacteria by detection of the polymorphism of PCR products of this region. ${ }^{36}$ The genome of many bacteria has multiple copies (alleles) of the rRNA operons. Within different operons, the size of the spacer region may vary which is related to the number and type of tRNA genes (tRNAglu, tRNAile, tRNAala) found in some spacer regions. ISRs show wider genetic variation as they are subjected to lower evolutionary pressure. ${ }^{37}$ The comparison between the three primers revealed that although Ribo2 gave $\mathrm{PM} \%=70$, its efficiency in the other parameters was better than Ribo-1 and Ribo-3 primers. Typeability, ISD, $\mathrm{H}_{\mathrm{g}}$, and EMR for Ribo-2 were $97.7 \%, 75 \%, 0.53$, and 9.80 , respectively and it gave 20 alleles ranging between 200-2000 bp that gave rise to 33 ribotypes. In contrast, Wolska and Szweda ${ }^{26}$ showed that Ribo-2 classified $62 P$. aeruginosa isolates into 9 types with $1-3$ bands ranging from $220-900 \mathrm{bp}$. The mean number of alleles, number of polymorphic and monomorphic bands per unit for the ribotyping technique were 12.67, 9.33, and 3.33, respectively, with EMR 6.9. In addition, the mean (\%) polymorphism was 75 . AZIMIRAD et al showed that PCR-ribotyping gave high discrimination of isolates as PFGE. ${ }^{38}$ Accordingly, our results revealed the high discriminatory power of Ribo-2 ( $\mathrm{DI}=0.969)$. Collier et al reported that PCR-ribotyping was more discriminating than AP-PCR in differentiating $49 P$. aeruginosa isolates. $^{39}$ Martin et al illustrated that using ribotyping was of little discrimination power with strains of P. aeruginosa. ${ }^{40}$

tDNA marker classified the isolates into 21 genotypes with genotype No.3 being the most pervasive one seen in $22.72 \%$ of isolates. A study conducted by Spacov et a ${ }^{10}$ using tDNA showed that tDNA had clustered 33 $P$. aeruginosa into 8 genotypes with genotype No.1 comprising about $79 \%$ of isolates. The number of alleles, polymorphic bands, monomorphic bands, and EMR were $16,11,5$, and 7.56, respectively. In addition, PM\% was 68.7 and DI was 0.921 where \% typeability was $97.7 \%$. Investigating the similarities between isolates showed that at $100 \%$ similarity among 7 clusters was found comprising 31 isolates.

ERIC-PCR typed $P$. aeruginosa isolates into 32 genotypes. Similar results were reported by Stehling et $\mathrm{al}^{27}$ where ERIC-PCR classified $62 P$. aeruginosa isolates into 25 genotypes. The number of alleles, polymorphic bands, monomorphic bands, and EMR were 21, 15, 6, and 10.71, respectively. The $\mathrm{H}_{\mathrm{g}}$, Mean PM (\%) and DI were $1.41,71.4$, and 0.964 , respectively. In contrast to our results, previous studies reported that ERIC-PCR showed the least discrimination power. ${ }^{27,41}$ Typeability was $81.8 \%$ where 8 isolates were untypable. Other studies reported the inability of ERIC-PCR to type some isolates of Plesiomonas shigelloides, ${ }^{42}$ and E. coli. ${ }^{43,44}$ At $100 \%$ similarity, ERIC gave five clusters with 18 isolates.

Calculation of DI of each typing method revealed that RAPD marker (P-640) has the highest power in discriminating isolates followed by Ribo-2 and ERIC. Higher discriminatory power does not always represent accurate epidemiologic relatedness. The effectiveness of a molecular typing method is a measure of the capability to form significant clustering and discrimination of the unrelated strains. ${ }^{45}$ Azimirad et al construct a correlation between RAPD, PFGE, and ribotyping in $C$. difficile isolates, they showed that the same discrimination power was obtained by PFGE and RAPD. ${ }^{38}$

In general, various methods were used to characterize $P$. aeruginosa strains. A vital point is how the use of a single method or combination of methods could provide information as DI, typeability, or ISD of the isolates. The comparison between typing methods permits the user to retain a convenient typing method and dismiss an inadequate one. $^{46}$

By comparing the four PCR-based methods used in this study, ERIC was the best marker used in most of the studied parameters indicating its potency in detecting genetic variation between isolates and its high polymorphic and discrimination power. The second best marker that can be used in discrimination was RAPD (P-640) followed by ribotyping (Ribo-2) then tDNA. Similar results were reported. ${ }^{41}$ Azimirad et al reported that RAPD and ERIC were the best markers in discrimination between $C$. difficile isolates followed by ribotyping. ${ }^{38}$ Besides, ribotyping using Ribo-2 primer was able to 
Table 6 Concordance Among Typing Methods According to Rand's Coefficient

\begin{tabular}{|c|c|c|c|c|c|c|c|c|c|c|}
\hline \multirow[t]{2}{*}{ Typing Method } & \multicolumn{10}{|c|}{ Rand's Coefficient } \\
\hline & D-I4306 & D- 10514 & OP-13 & OPA-O2 & P-640 & AP3 & Ribo-I & Ribo-2 & Ribo-3 & tDNA \\
\hline D-I 4306 & & & & & & & & & & \\
\hline D- 10514 & 0.586 & & & & & & & & & \\
\hline OP-13 & 0.621 & 0.893 & & & & & & & & \\
\hline OP-O2 & 0.628 & 0.871 & 0.872 & & & & & & & \\
\hline P-640 & 0.615 & 0.928 & 0.919 & 0.894 & & & & & & \\
\hline AP3 & 0.648 & 0.874 & 0.856 & 0.836 & 0.891 & & & & & \\
\hline Ribo-I & 0.479 & 0.699 & 0.660 & 0.642 & 0.690 & 0.677 & & & & \\
\hline Ribo-2 & 0.627 & 0.921 & 0.924 & 0.891 & 0.948 & 0.892 & 0.685 & & & \\
\hline Ribo-3 & 0.593 & 0.773 & 0.793 & 0.756 & 0.792 & 0.742 & 0.598 & 0.795 & & \\
\hline tDNA & 0.606 & 0.876 & $0.87 I$ & 0.842 & 0.904 & 0.846 & 0.662 & 0.894 & 0.755 & \\
\hline ERIC & 0.607 & 0.922 & 0.906 & 0.875 & 0.939 & 0.893 & 0.709 & 0.936 & 0.783 & 0.887 \\
\hline
\end{tabular}

differentiate $75 \%$ of isolates followed by ERIC $(72.72 \%)$ and P-640 primer (70\%). Oleńska and Małek found that ERIC-PCR can differentiate $61 \%$ of 77 rhizobial strains. ${ }^{30}$ Moreover, ERIC was the best one in detecting the conserved regions in the genome followed by tDNA, RAPD, and ribotyping as the number of monomorphic bands per assay unit for them were $6,5,4.33$, and 3.33 , respectively.

Previous studies reported the usefulness of ERIC-PCR in detecting the difference in number and distribution of repetitive alleles in isolates as $P$. aeruginosa isolates ${ }^{47,48}$ E. coli $^{49}$ and Leptospira isolates ${ }^{45}$ with high typeability $\%$, DI and ISD. ERIC-PCR is cheaper, easier to perform, reliable, rapid in addition to its high discrimination power. All these factors facilitate its use in the epidemiology of $P$. aeruginosa in Australia and Brazil. ${ }^{50,51}$

All permutations of combinations of two types were analyzed and all combinations resulted in increased DI. The trend toward using more than one type for analysis was previously used by Clark et al who reported higher DI using combinations of more than one typing method than using either alone. ${ }^{52}$ Wolska and Szweda ${ }^{26}$ and Stehling et $\mathrm{al}^{27}$ proposed that the combination of ribotyping with other PCR-typing methods or traditional techniques can give extreme discrimination of $P$. aeruginosa. Combining ERIC with RAPD primers (OPA-02 and P-640) increased the DI to 1 as 44 types were obtained. Moreover, typeability increased to $100 \%$ as the isolates that could not be typed by one method were typed by the combined one.

The congruence between typing methods indicates the probability that pairs of isolates that are assigned to the same type by one typing method are also typed as identical by the other. The congruence between typing methods determined by Rand's coefficient revealed that D-15014 and OP-13types were best predicted by P-640, Ribo-2, and ERIC. While P-640-types were best predicted by Ribo-2 and ERIC. AP3-, Ribo-1-, Ribo-2-, Ribo-3- and tDNA-types were best predicted by ERIC. Evaluation of the congruence among combinations of typing methods by Rand's coefficient indicated a high increase in the coefficient of all markers where $\mathrm{R}=1$ in ERIC+OPA-02 using ERIC+P-640.

Evaluation of the congruence between typing methods using the Wallace coefficient showed that only D-14306- types and AP3; Ribo-1-types and ERIC showed moderate congruence $(0.427$ and 0.536 , respectively) with $95 \%$ CI. The other typing methods showed no or poor congruence suggesting that they grouped the tested isolates in different ways. The Wallace coefficient values among combinations of ERIC with typing methods were very high indicating complete congruence $(\mathrm{W}=1)$. Clark et al found complete congruent and higher Wallace coefficient values when the method of a higher resolution was used. ${ }^{52}$ Worth mentioning that ERIC +OPA-02 and ERIC+P-640 combinations were the highest resolution methods $(\mathrm{DI}=1)$ and showed complete congruence with all other combinations when used as the secondary methods. ERIC + Ribo- 1 combination gave high to complete congruence when used as the primary method. Following our results, Faria et al found that combining two typing methods (PFGE typespa type combination) increased the predictive power of each method for determining the SCCmec type in Staphylococcus aureus. ${ }^{15}$ 


\begin{tabular}{|c|c|c|c|c|c|c|c|c|c|c|c|c|c|}
\hline & \multicolumn{2}{|l|}{$\frac{u}{\underline{u}}$} & 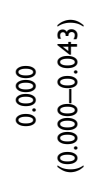 & 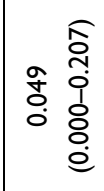 & $\begin{array}{rl} & \widehat{\circ} \\
0 & 0 \\
0 & 0 \\
0 & 0 \\
0 & 0 \\
0 & 0 \\
0\end{array}$ & 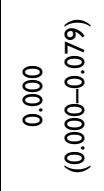 & 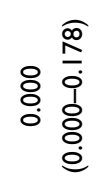 & 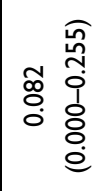 & 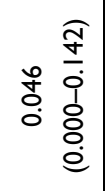 & o & 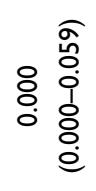 & 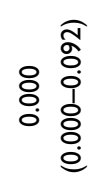 & \\
\hline & \multicolumn{2}{|l|}{$\underset{Q}{\mathbb{2}}$} & 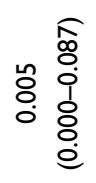 & $\begin{array}{r} \\
\\
0 \\
0 \\
0 \\
0 \\
0 \\
0 \\
0\end{array}$ & 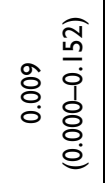 & 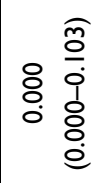 & 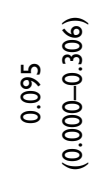 & 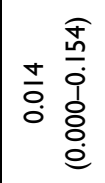 & $\begin{array}{rl} & \widehat{o} \\
0 & 0 \\
0 & 0 \\
0 & 0 \\
0 & 0 \\
0\end{array}$ & 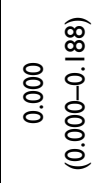 & $\begin{array}{ll} & \widehat{a} \\
\text { o. } & \\
\text { o. } \\
0 \\
0\end{array}$ & & o \\
\hline & \multirow{3}{*}{ 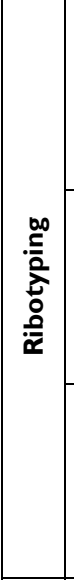 } & $\begin{array}{l}\tilde{\partial} \\
\dot{\hat{\alpha}}\end{array}$ & 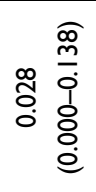 & 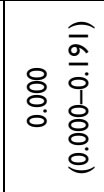 & 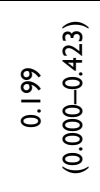 & 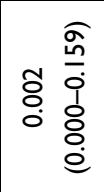 & 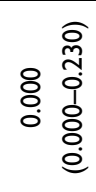 & 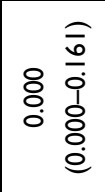 & 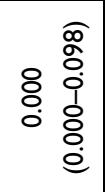 & 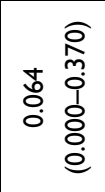 & & 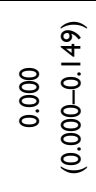 & 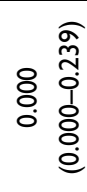 \\
\hline & & 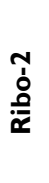 & 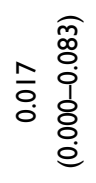 & 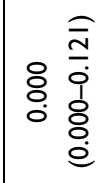 & 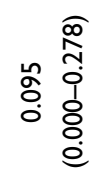 & 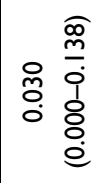 & 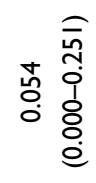 & 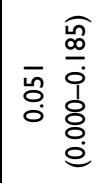 & 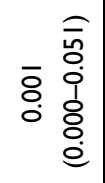 & & 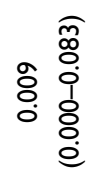 & 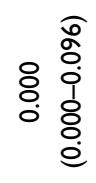 & 定 \\
\hline & & 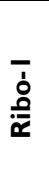 & 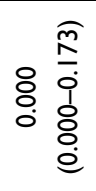 & 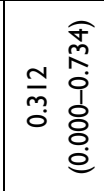 & $\begin{array}{ll} & \frac{\widehat{n}}{N} \\
8 & 0 \\
0 & 0 \\
0 & 0 \\
0 & 0\end{array}$ & 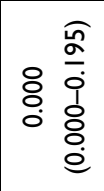 & 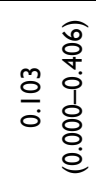 & 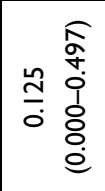 & & 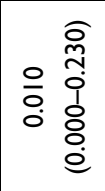 & 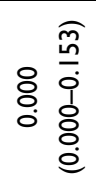 & 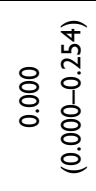 & 施 \\
\hline & & $\stackrel{\tilde{q}}{<}$ & 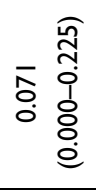 & 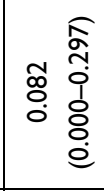 & 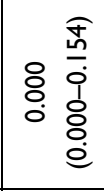 & 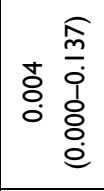 & 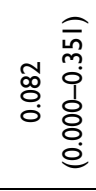 & & 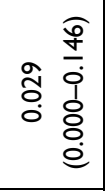 & 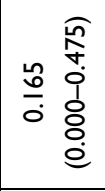 & 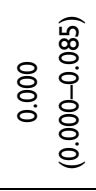 & 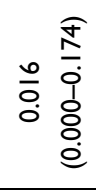 & 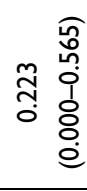 \\
\hline & & $\begin{array}{l}\frac{0}{0} \\
0 \\
d\end{array}$ & 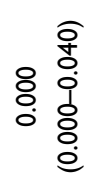 & 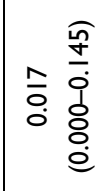 & 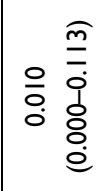 & 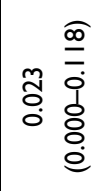 & & 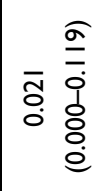 & 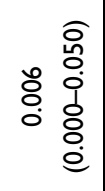 & 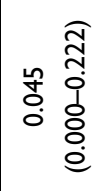 & 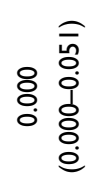 & 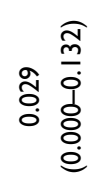 & 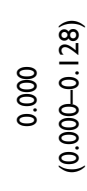 \\
\hline & $a$ & $\begin{array}{l}\text { ô } \\
\text { ¿̇ }\end{array}$ & 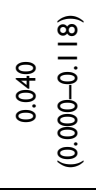 & 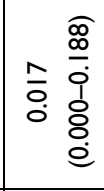 & 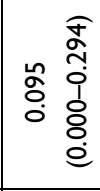 & & 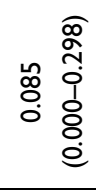 & 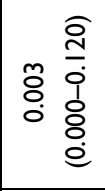 & 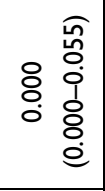 & 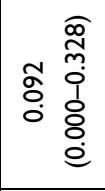 & $\begin{array}{l}\text { 盛 } \\
\overline{0} \\
\vdots \\
0 \\
0\end{array}$ & 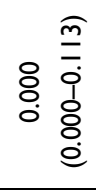 & 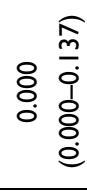 \\
\hline & $\approx$ & $\AA_{0}^{\prime}$ & 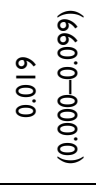 & 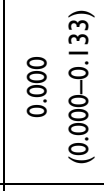 & & 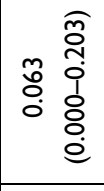 & 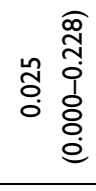 & 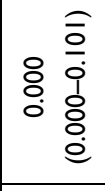 & 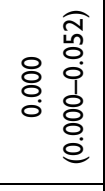 & 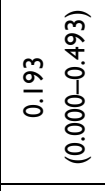 & 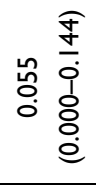 & 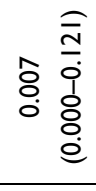 & $\begin{array}{l}\frac{\widehat{n}}{2} \\
\circ \\
0 \\
0 \\
0\end{array}$ \\
\hline & & $\frac{\frac{\sigma}{0}}{\frac{\Delta}{\partial}}$ & 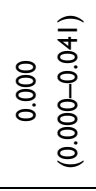 & & 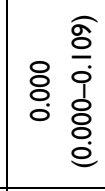 & 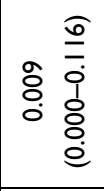 & 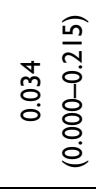 & 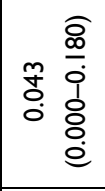 & 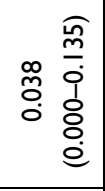 & $\begin{array}{r}\frac{\sigma}{0} \\
0 \\
0 \\
0 \\
0 \\
0 \\
0\end{array}$ & 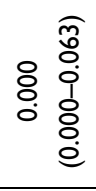 & $\begin{array}{l}\frac{\widehat{\sigma}}{0} \\
\text { o. } \\
0 \\
0 \\
0\end{array}$ & 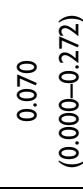 \\
\hline & & $\begin{array}{l}\stackrel{\circ}{\sigma} \\
\frac{\tilde{\sigma}}{\dot{\alpha}}\end{array}$ & & $\begin{array}{ll} & \widehat{\mathbb{Z}} \\
0 & 0 \\
0 \\
0 \\
0 \\
0\end{array}$ & 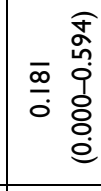 & 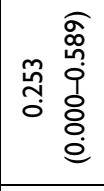 & $\begin{array}{ll} & \widehat{P} \\
0 \\
0 \\
0 \\
0 \\
0 \\
0 \\
0 \\
0\end{array}$ & 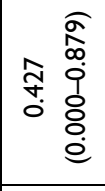 & 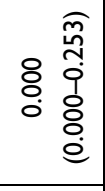 & 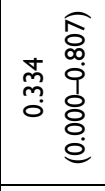 & 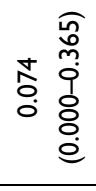 & 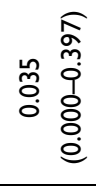 & 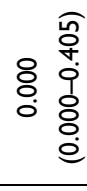 \\
\hline & \multicolumn{2}{|c|}{ : } & r্ & $\begin{array}{l}\frac{\sigma}{\Delta} \\
\frac{\partial}{\dot{b}}\end{array}$ & $\frac{m}{\grave{d}}$ & $\begin{array}{l}\text { ô } \\
\vdots \\
\text { on }\end{array}$ & $\begin{array}{l}\text { 京 } \\
0 \\
0\end{array}$ & $\frac{2}{4}$ & $\begin{array}{l}\overline{\hat{o}} \\
\text { 产 }\end{array}$ & $\begin{array}{l}\text { Oे } \\
\text { de }\end{array}$ & 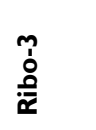 & $\begin{array}{l}\underline{z} \\
\underline{Q}\end{array}$ & $\frac{\underline{u}}{\tilde{w}}$ \\
\hline
\end{tabular}




\begin{tabular}{|c|c|c|c|c|c|c|c|c|c|c|c|}
\hline \multirow{11}{*}{ 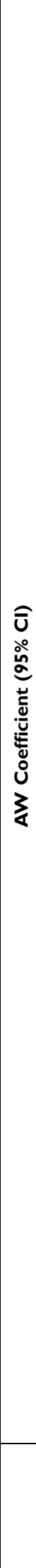 } & 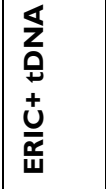 & 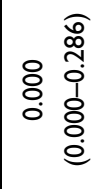 & 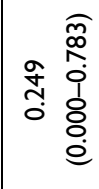 & 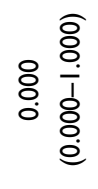 & 安 & o & 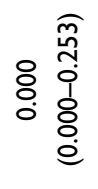 & 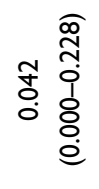 & 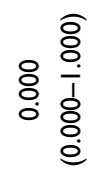 & 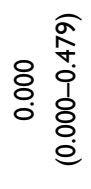 & \\
\hline & 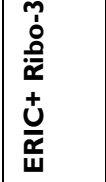 & 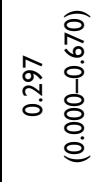 & 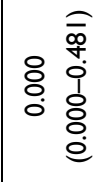 & 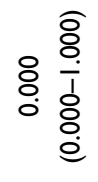 & 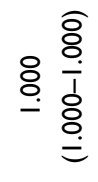 & 安 & 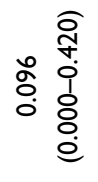 & 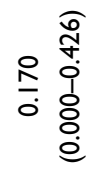 & 安 & & 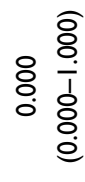 \\
\hline & $\begin{array}{l}\tilde{o} \\
\dot{0} \\
\tilde{\alpha} \\
+ \\
\frac{0}{\tilde{u}}\end{array}$ & 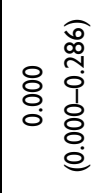 & 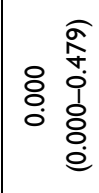 & 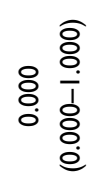 & 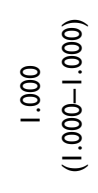 & o & 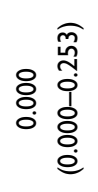 & 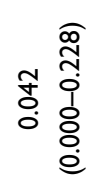 & & 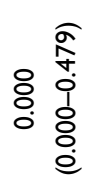 & \& $\frac{\widehat{\circ}}{0}$ \\
\hline & 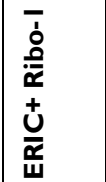 & 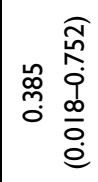 & 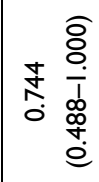 & هo & 客 & 这 & 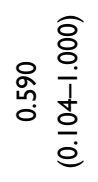 & & 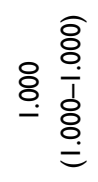 & 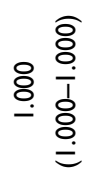 & ه \\
\hline & 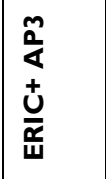 & 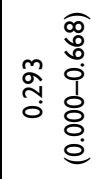 & 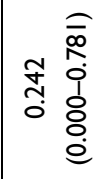 & 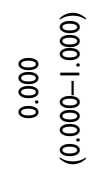 & 官 & 这 & & 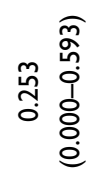 & 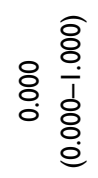 & 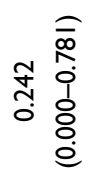 & \& $\frac{\widehat{\circ}}{\circ}$ \\
\hline & 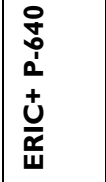 & 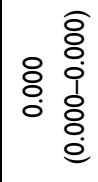 & 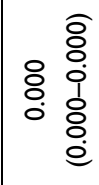 & 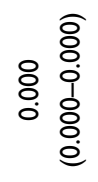 & 官 & & 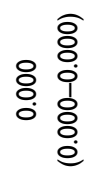 & 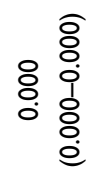 & 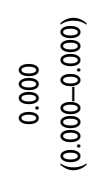 & 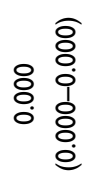 & 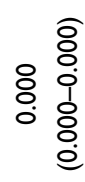 \\
\hline & 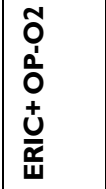 & 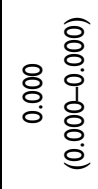 & 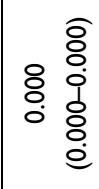 & 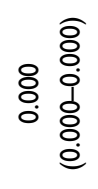 & & 安 & 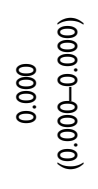 & 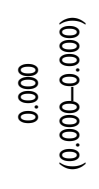 & 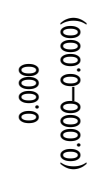 & 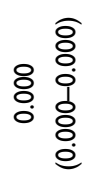 & 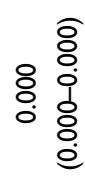 \\
\hline & $\begin{array}{l}\frac{m}{1} \\
\frac{1}{0} \\
\frac{t}{\tilde{u}}\end{array}$ & 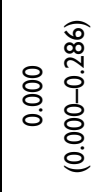 & 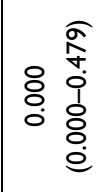 & & 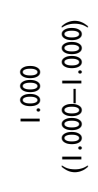 & 安 & 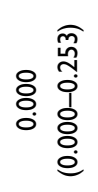 & 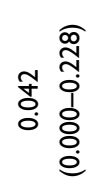 & 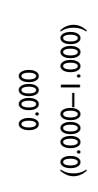 & 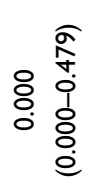 & 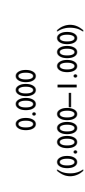 \\
\hline & 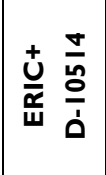 & 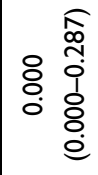 & & 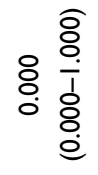 & 客 & 官 & 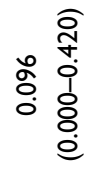 & 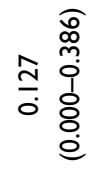 & 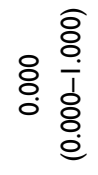 & 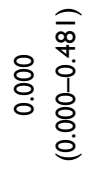 & 迢 \\
\hline & 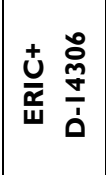 & & 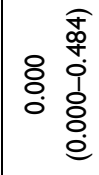 & 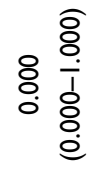 & 官 & 这 & 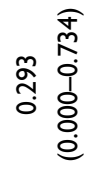 & 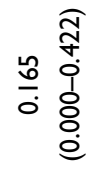 & 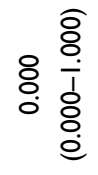 & 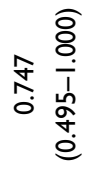 & 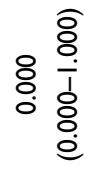 \\
\hline & 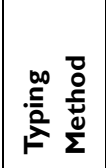 & 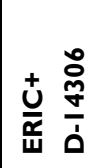 & 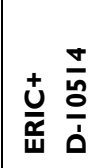 & $\begin{array}{l}\dot{0} \\
0 \\
\dot{t} \\
\frac{\tilde{U}}{\tilde{u}} \underline{m}\end{array}$ & $\begin{array}{l}0 \\
0 \\
\frac{ \pm}{\tilde{U}} \\
\tilde{u}\end{array}$ & 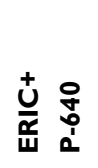 & $\begin{array}{l}\frac{m}{\alpha} \\
\dot{U} \\
\frac{\tilde{Q}}{\tilde{u}}\end{array}$ & 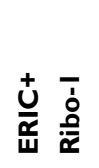 & 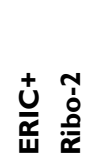 & 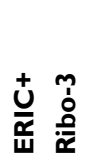 & 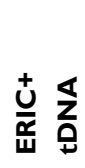 \\
\hline
\end{tabular}




\section{Conclusion}

Based on the results obtained, the genetic diversity of 44 isolates of $P$. aeruginosa were analyzed using primers of RAPD, ribotyping, tDNA, and ERIC. All the PCR-typing methods are useful for epidemiological typing of $P$. aeruginosa isolates as they are simple and fast methods. ERIC-PCR and RAPD-PCR showed the highest performance in discriminating isolates. The usage of two or more typing methods in combination may result in a better evaluation of the genetic diversity of isolates. The performance characteristics of ERIC and its combinations make them the most suitable typing methods for epidemiological analysis. So, we suggest their use to study the genetic diversity of $P$. aeruginosa. The application of two or more typing methods in combination may result in a better discrimination of isolates.

\section{Acknowledgments}

We would like to thank the Urology and Nephrology Centre for providing the clinical isolates. This study was performed at the Microbiology and Immunology Department, Faculty of Pharmacy, Mansoura University, Mansoura, Egypt.

\section{Disclosure}

The authors report no conflicts of interest in this work.

\section{References}

1. Pachori P, Gothalwal R, Gandhi P. Emergence of antibiotic resistance Pseudomonas aeruginosa in intensive care unit; a critical review. Genes Dis. 2019;6(2):109-119. doi:10.1016/j.gendis.2019.04.001

2. Liu T, Zhang Y, Wan Q. Pseudomonas aeruginosa bacteremia among liver transplant recipients. Infect Drug Resist. 2018;11:2345-2356. doi:10.2147/IDR.S180283

3. Li W, Raoult D, Fournier PE. Bacterial strain typing in the genomic era. FEMS Microbiol Rev. 2009;33(5):892-916. doi:10.1111/j.15746976.2009.00182.x

4. MacCannell D. Bacterial strain typing. Clin Lab Med. 2013;33 (3):629-650. doi:10.1016/j.cll.2013.03.005

5. Ranjbar R, Karami A, Farshad S, Giammanco GM, Mammina C. Typing methods used in the molecular epidemiology of microbial pathogens: a how-to guide. New Microbiol. 2014;37(1):1-15.

6. Aljindan R, Alsamman K, Elhadi N. ERIC-PCR genotyping of Acinetobacter baumannii isolated from different clinical specimens. Saudi J Med Med Sci. 2018;6(1):13-17. doi:10.4103/sjmms. sjmms_138_16

7. Rodriguez JM, Lopez-Romalde S, Beaz R, Alonso MC, Castro D, Romalde JL. Molecular fingerprinting of Vibrio tapetis strains using three PCR-based methods: ERIC-PCR, REP-PCR and RAPD. Dis Aquat Organ. 2006;69(2):175-183. doi:10.3354/dao069175

8. Uddin MS, Cheng Q. Recent application of biotechniques for the improvement of mango research. In: Poltronieri P, Hong Y, editors. Applied Plant Genomics and Biotechnology. Woodhead Publishing; 2015:195-212.
9. Waturangi DE, Joanito I, Yogi Y, Thomas S. Use of REP- and ERIC-PCR to reveal genetic heterogeneity of Vibrio cholerae from edible ice in Jakarta, Indonesia. Gut Pathog. 2012;4(1):2. doi:10.1186/1757-4749-4-2

10. Spacov ICG, Silva S, Júnior M, Morais M. Polymorphism of the rDNA and tDNA loci in clinical isolates of Pseudomonas aeruginosa: a perspective for molecular epidemiology surveillance. Genet $\mathrm{Mol}$ Biol. 2006;29(4):722-729. doi:10.1590/S1415-47572006000400023

11. Adzitey F, Huda N, Ali GR. Molecular techniques for detecting and typing of bacteria, advantages and application to foodborne pathogens isolated from ducks. 3 Biotech. 2013;3(2):97-107. doi:10.1007/ s13205-012-0074-4

12. Van Looveren $M$, Ison CA, Ieven M, et al. Evaluation of the discriminatory power of typing methods for Neisseria gonorrhoeae. J Clin Microbiol. 1999;37(7):2183-2188. doi:10.1128/ JCM.37.7.2183-2188.1999

13. Burucoa C, Lhomme V, Fauchere JL. Performance criteria of DNA fingerprinting methods for typing of Helicobacter pylori isolates: experimental results and meta-analysis. J Clin Microbiol. 1999;37 (12):4071-4080. doi:10.1128/JCM.37.12.4071-4080.1999

14. Welsh J, McClelland M. Fingerprinting genomes using PCR with arbitrary primers. Nucleic Acids Res. 1990;18(24):7213-7218. doi:10.1093/nar/18.24.7213

15. Faria NA, Carrico JA, Oliveira DC, Ramirez M, de Lencastre H. Analysis of typing methods for epidemiological surveillance of both methicillin-resistant and methicillin-susceptible Staphylococcus aureus strains. J Clin Microbiol. 2008;46(1):136-144. doi:10.1128/ JCM.01684-07

16. Englen M, Kelley LC. A rapid DNA isolation procedure for the identification of Campylobacter jejuni by the polymerase chain reaction. Lett Appl Microbiol. 2008;31:421-426. doi:10.1046/ j.1365-2672.2000.00841.x

17. Deligianni E, Pattison S, Berrar D, et al. Pseudomonas aeruginosa cystic fibrosis isolates of similar RAPD genotype exhibit diversity in biofilm forming ability in vitro. BMC Microbiol. 2010;10:38. doi:10.1186/1471-2180-10-38

18. Scaccabarozzi L, Leoni L, Ballarini A, et al. Pseudomonas aeruginosa in dairy goats: genotypic and phenotypic comparison of intramammary and environmental isolates. PLoS One. 2015;10(11): e0142973. doi:10.1371/journal.pone.0142973

19. Jana T, Sharma TR, Prasad RD, Arora DK. Molecular characterization of Macrophomina phaseolina and Fusarium species by a single primer RAPD technique. Microbiol Res. 2003;158(3):249-257. doi:10.1078/0944-5013-00198

20. Sazakli E, Leotsinidis M, Vantarakis A, Papapetropoulou M. Comparative typing of Pseudomonas species isolated from the aquatic environment in Greece by SDS-PAGE and RAPD analysis. J Appl Microbiol. 2005;99 (5):1191-1203. doi:10.1111/j.1365-2672.2005.02691.x

21. Eftekhar F, Nouri P. Correlation of RAPD-PCR profiles with ESBL production in clinical isolates of Klebsiella pneumoniae in Tehran. J Clin Diagn Res. 2015;9(1):DC01-03. doi:10.7860/JCDR/2015/ 10651.5373

22. Abou-Dobara MI, Deyab MA, Elsawy EM, Mohamed HH. Antibiotic susceptibility and genotype patterns of Escherichia coli, Klebsiella pneumoniae and Pseudomonas aeruginosa isolated from urinary tract infected patients. Pol J Microbiol. 2010;59(3):207-212. doi:10.33073/pjm-2010-032

23. Sumbria D, Singla LD, Sharma A, Moudgil AD, Bal MS. Equine trypanosomosis in central and western Punjab: prevalence, haemato-biochemical response and associated risk factors. Acta Trop. 2014;138:44-50. doi:10.1016/j.actatropica.2014.06.003

24. Green LM, Worthington T, Hilton AC, Lambert PA. Genetic characterization of clinical isolates of Clostridium difficile using an optimized RAPD protocol and PCR ribotyping reveals strain diversity between two tertiary referral Trusts in the West Midlands, UK. J Med Microbiol. 2011;60(Pt 9):1287-1291. doi:10.1099/jmm.0.030999-0 
25. Satpathy G, Patnayak D, Titiyal JS, et al. Post-operative endophthalmitis: antibiogram \& genetic relatedness between Pseudomonas aeruginosa isolates from patients \& phacoemulsifiers. Indian J Med Res. 2010;131:571-577.

26. Wolska K, Szweda P. A comparative evaluation of PCR ribotyping and ERIC PCR for determining the diversity of clinical Pseudomonas aeruginosa isolates. Pol J Microbiol. 2008;57(2):157-163.

27. Stehling EG, Leite DS, Silveira WD. Molecular typing and biological characteristics of Pseudomonas aeruginosa isolated from cystic fibrosis patients in Brazil. Braz J Infect Dis. 2010;14(5):462-467. doi:10.1016/S1413-8670(10)70094-5

28. Sornakili A, Rathinam P, Thiruvengadum R, Kuppusamy P. Comparative assessment of RAPD and ISSR markers to study genetic polymorphism in Colletotrichum gloeosorioides isolates of Mango. Asian J Plant Pathol. 2017;11:130-138. doi:10.3923/ ajppaj.2017.130.138

29. Mariette S, Le Corre V, Austerlitz F, Kremer A. Sampling within the genome for measuring within-population diversity: trade-offs between markers. Mol Ecol. 2002;11(7):1145-1156. doi:10.1046/ j.1365-294X.2002.01519.x

30. Olenska E, Malek W. Genomic polymorphism of Trifolium repens root nodule symbionts from heavy metal-abundant 100-year-old waste heap in southern Poland. Arch Microbiol. 2019;201 (10):1405-1414. doi:10.1007/s00203-019-01708-x

31. Hunter PR, Gaston MA. Numerical index of the discriminatory ability of typing systems: an application of Simpson's index of diversity. J Clin Microbiol. 1988;26(11):2465-2466. doi:10.1128/ JCM.26.11.2465-2466.1988

32. Carrico JA, Silva-Costa C, Melo-Cristino J, et al. Illustration of a common framework for relating multiple typing methods by application to macrolide-resistant Streptococcus pyogenes. J Clin Microbiol. 2006;44(7):2524-2532. doi:10.1128/JCM.02536-05

33. Singh JP, Verma R, Chaudhuri P. Random amplified polymorphic DNA (RAPD) analysis of Mycobacterium tuberculosis strains in India. J Vet Sci. 2006;7(2):181-187. doi:10.4142/jvs.2006.7.2.181

34. Pethannan R, Kuppuswamy AC, Gupta R, et al. RAPD characterization of pseudomonas species identified from clinical samples. Recent Res Sci Technol. 2018;10:11-15.

35. Daly M, Power E, Bjorkroth J, et al. Molecular analysis of Pseudomonas aeruginosa: epidemiological investigation of mastitis outbreaks in Irish dairy herds. Appl Environ Microbiol. 1999;65 (6):2723-2729. doi:10.1128/AEM.65.6.2723-2729.1999

36. Kostman JR, Alden MB, Mair M, Edlind TD, LiPuma JJ, Stull TL. A universal approach to bacterial molecular epidemiology by polymerase chain reaction ribotyping. J Infect Dis. 1995;171(1):204-208. doi:10.1093/infdis/171.1.204

37. Garcia-Martinez J, Acinas SG, Anton AI, Rodriguez-Valera F. Use of the $16 \mathrm{~S}-23 \mathrm{~S}$ ribosomal genes spacer region in studies of prokaryotic diversity. J Microbiol Methods. 1999;36(1-2):55-64. doi:10.1016/ S0167-7012(99)00011-1

38. Azimirad M, Alebouyeh M, Rashidan M, Aslani MM, Zali MR. Comparison of common molecular typing methods for differentiation of Clostridium difficile strains in the study of hospital acquired diarrhea. Arch Clin Infect Dis. 2018;13:5.
39. Collier JG, Fraser GA, Marmion PB, Simmons A. Practical medical microbiology. Churchill Livingstone, NY. 1996;4:413-418.

40. Martin C, Ichou MA, Massicot P, Goudeau A, Quentin R. Genetic diversity of Pseudomonas aeruginosa strains isolated from patients with cystic fibrosis revealed by restriction fragment length polymorphism of the rRNA gene region. J Clin Microbiol. 1995;33 (6):1461-1466. doi:10.1128/JCM.33.6.1461-1466.1995

41. Liu Y, Davin-Regli A, Bosi C, Charrel RN, Bollet C. Epidemiological investigation of Pseudomonas aeruginosa nosocomial bacteraemia isolates by PCR-based DNA fingerprinting analysis. $J \mathrm{Med}$ Microbiol. 1996;45(5):359-365. doi:10.1099/00222615-45-5-359

42. Ekundayo T, Okoh A. Molecular characterization, intra-species diversity and abundance of freshwater Plesiomonas shigelloides isolates. Microorganisms. 2020;8(7):1081. doi:10.3390/microorganisms8071081

43. Ekundayo TC, Okoh AI, Sibai AM. A global bibliometric analysis of Plesiomonas-related research (1990-2017). PLoS One. 2018;13(11): e0207655. doi:10.1371/journal.pone.0207655

44. Ekundayo TC, Okoh AI. Modelling the effects of physicochemical variables and anthropogenic activities as ecological drivers of Plesiomonas shigelloides distribution and freshwaters quality. Sci Total Environ. 2019;682:765-778. doi:10.1016/j.scitotenv.2019.05.129

45. Bilung LM, Pui CF, Su'ut L, Apun K. Evaluation of BOX-PCR and ERIC-PCR as molecular typing tools for pathogenic leptospira. Dis Markers. 2018;2018:1351634. doi:10.1155/2018/1351634

46. Ghazi F, Kihal M, Altay N, Gürakan GC. Comparison of RAPD-PCR and PFGE analysis for the typing of Streptococcus thermophilus strains isolated from traditional Turkish yogurts. Ann Microbiol. 2016;66:1013-1026. doi:10.1007/s13213-015-1185-z

47. Hernández M, Castillo G, Ramos OC, et al. Molecular characterization of Pseudomonas aeruginosa clinical isolates among patients of the Hospital Del Niño, Republic Of Panama. Internet J Microbiol. 2016;14(1).

48. Han MM, Mu LZ, Liu XP, Zhao J, Liu XF, Liu H. ERIC-PCR genotyping of Pseudomonas aeruginosa isolates from haemorrhagic pneumonia cases in mink. Vet Rec Open. 2014;1(1):e000043. doi:10.1136/vropen-2014-000043

49. Saha O, Hoque MN, Islam OK, Rahaman MM, Sultana M, Hossain MA. Multidrug-resistant avian pathogenic Escherichia coli strains and association of their virulence genes in Bangladesh. Microorganisms. 2020;8 (8):1135. doi:10.3390/microorganisms8081135

50. Khosravi AD, Hoveizavi H, Mohammadian A, Farahani A, Jenabi A. Genotyping of multidrug-resistant strains of Pseudomonas aeruginosa isolated from burn and wound infections by ERIC-PCR. Acta Cir Bras. 2016;31(3):206-211. doi:10.1590/S0102-865020160030000009

51. Zarei O, Shokoohizadeh L, Hossainpour H, Alikhani MY. Molecular analysis of Pseudomonas aeruginosa isolated from clinical, environmental and cockroach sources by ERIC-PCR. BMC Res Notes. 2018;11(1):668. doi:10.1186/s13104-018-3765-z

52. Clark CG, Taboada E, Grant CC, et al. Comparison of molecular typing methods useful for detecting clusters of Campylobacter jejuni and $C$. coli isolates through routine surveillance. J Clin Microbiol. 2012;50(3):798-809. doi:10.1128/JCM.05733-11 


\section{Publish your work in this journal}

Infection and Drug Resistance is an international, peer-reviewed openaccess journal that focuses on the optimal treatment of infection (bacterial, fungal and viral) and the development and institution of preventive strategies to minimize the development and spread of resistance. The journal is specifically concerned with the epidemiology of antibiotic resistance and the mechanisms of resistance development and diffusion in both hospitals and the community. The manuscript management system is completely online and includes a very quick and fair peerreview system, which is all easy to use. Visit http://www.dovepress.com/ testimonials.php to read real quotes from published authors.

Submit your manuscript here: https://www.dovepress.com/infection-and-drug-resistance-journal 